\title{
Role of miR-149C $>$ T polymorphisms on the risk of hepatocellular carcinoma in a Chinese population
}

\author{
M.F. Liu, W.Q. Chen, Y.Z. He and Y.L. Gu \\ Department of Hepatopancreatobiliary Surgery, Wuxi Third People's Hospital, \\ Wuxi, Jiangsu Province, China \\ Corresponding author: Y.L. Gu \\ E-mail: guyuanlong_wtp@yeah.net
}

Genet. Mol. Res. 13 (3): 7184-7189 (2014)

Received November 7, 2013

Accepted April 3, 2014

Published September 5, 2014

DOI http://dx.doi.org/10.4238/2014.September.5.4

\begin{abstract}
MicroRNAs (miRNAs) are thought to play a role in cancer development. We conducted a case-control study to investigate the association between polymorphisms in miR-149C $>\mathrm{T}$ and hepatocellular carcinoma (HCC) risk. Duplex polymerase chain reaction with the confronting 2-pair primers were taken to genotype miR-149C $>$ T. The association between genotype frequencies of miR-149C $>\mathrm{T}$ and risk of $\mathrm{HCC}$ was estimated as odds ratios (ORs) and 95\% confidence intervals (95\%CIs) using conditional regression analysis. Logistical regression analysis showed that the miR-149 CC genotype and $\mathrm{C}$ allele were associated with risk of HCC, with adjusted ORs $(95 \% \mathrm{CI})$ of 2.07 (1.32$3.26)$ and 1.42 (1.06-2.12), respectively. Using the TT+TC genotype as a reference, individuals carrying the $\mathrm{CC}$ genotype were associated with non-significant increased risk of HCC, adjusted OR $(95 \% \mathrm{CI})$ of 1.37 (0.91-2.07). Subgroup analysis showed that HBV-infected subjects carrying the miR-149 $\mathrm{TC}+\mathrm{CC}$ genotype $(\mathrm{OR}=5.85,95 \% \mathrm{CI}=2.49$ 13.77) had an increased risk of HCC. In summary, our study found
\end{abstract}


that miRNA-149C $>$ T polymorphism is associated with risk of $\mathrm{HCC}$, especially in HBV-infected patients.

Key words: Hepatocellular carcinoma; miR-149C>T;

Polymorphisms; HCC risk

\section{INTRODUCTION}

In China, hepatocellular carcinoma (HCC) deaths account for $50 \%$ of all liver cancer deaths worldwide (IARC, 2008), and it has the 4th highest mortality rate with estimated 109,242 new cases per year in China (IARC, 2008). Exposure to hepatitis B virus (HBV) infection is a well known risk factor for developing HCC (Kao and Chen, 2002). However, only a few HBV-infected individuals developed HCC during their lifetime, which means that genetic and environmental factors have a role in susceptibility of HCC.

MicroRNAs (miRNAs) have a role in physiological and pathological conditions, such as development, cellular differentiation and cell death as well as metabolism (Hatfield et al., 2005). Previous studies have shown that miRNAs can influence the development of cancer by regulating the expression of tumor suppressor genes (Esquela-Kerscher and Slack, 2006; Calin and Croce, 2006). It is well known that single-nucleotide polymorphisms are the most common genetic variations in the human genome (Mishra and Bertino, 2009), which can alter protein expression, and thus influence an individual's susceptibility to various cancers (Chu et al., 2014). A C $>$ T genetic polymorphism is found in the miR-149C $>\mathrm{T}$ gene and is located in the stem region next to the mature miR-149C $>\mathrm{T}$ sequence. miR-149C $>\mathrm{T}$ polymorphisms are associated with risk of several cancers, such as colorectal cancer, hepatocellular carcinoma, esophageal cancer, cervical cancer, and prostate cancer (Jang et al., 2011; Kim et al., 2012; He et al., 2012). We conducted a case-control study to investigate the association between polymorphisms in miR-149C $>\mathrm{T}$ and $\mathrm{HCC}$ risk.

\section{MATERIAL AND METHODS}

\section{Study population}

From September 2008 to June 2012, 327 cases who were diagnosed to be HCC by liver biopsy were included into our study. At the same time, 327 controls were collected from health check-up center and matched to cases by gender and age. Control subjects who had a history of cancer were excluded from this study. The protocol of this study was approved by the institutional Ethnics Committee of Wuxi Third People's Hospital, and informed consents were obtained from all participates before enrolling into our study.

\section{DNA extraction and genotyping}

The cases and controls were asked to provide 5-mL whole-blood samples. Duplex polymerase chain reaction (PCR) with the confronting 2-pair primers were taken to genotype miR-149C $>$ T. The PCR primers for miR-149C $>$ T were designed by the Sequenom ${ }^{\circledR}$ Assay Design version 3.1 software (Sequenom ${ }^{\circledR}$; San Diego, CA, USA). The forward primer for 
miR-149C > T were 5'-TGT CTT CAC TCC CGT GCT TGT CC-3' and reverse 5'-TGA GGC CCG AAA CAC CCG TA-3'. The miR-149C $>$ T was digested at $37^{\circ} \mathrm{C}$ for $16 \mathrm{~h}$ with AluI. The reaction product $(12 \mu \mathrm{L})$ was run on a $3.0 \%$ agarose gel, stained with ethidium bromide and directly visualized under ultraviolet illumination. For quality control, $5 \%$ of the cases and control subjects were chosen to genotype, and concordance of these samples with the previous results was $100 \%$.

\section{Statistical analysis}

The association between genotype frequencies of miR-149C $>\mathrm{T}$ and risk of $\mathrm{HCC}$ was estimated as odds ratios (ORs) and $95 \%$ confidence intervals $(95 \% \mathrm{CIs})$ using conditional regression analysis and adjusted for potential gender, smoking, drinking, and hepatitis B or C virus infection. $\mathrm{P}<0.05$ was considered to be statistically significant. All statistical analyses were conducted using the Statistical Package for Social Science version 17.0 software (SPSS Inc.; Chicago, IL, USA).

\section{RESULTS}

The 327 HCC patients were comprised of 103 women and 224 men, and the mean age of these HCC cases was $56.2 \pm 11.3$ years. The 327 control subjects were also comprised of 224 men and 103 women, and the mean age was $55.8 \pm 10.7$ years (Table 1). By comparing demographic and clinical characteristics, HCC patients were more likely to be alcohol drinkers, and have $\mathrm{HBV}$ and hepatitis $\mathrm{C}$ virus $(\mathrm{HCV})$ infection. The ORs $(95 \% \mathrm{CI})$ for alcohol consumption, HBV and HCV infection were 1.49 (1.06-2.11), 6.14(4.01-9.50), and 9.43 (3.77-28.07), respectively. The 127 (38.84\%) patients had tumor size $\geq 5 \mathrm{~cm}$, and $195(59.63 \%)$ were at stage I-II TNM classification.

\begin{tabular}{|c|c|c|c|c|c|c|c|}
\hline \multirow[t]{2}{*}{ Variables } & \multicolumn{2}{|c|}{ Cases } & \multicolumn{2}{|c|}{ Controls } & \multirow[t]{2}{*}{$\chi^{2}$} & \multirow[t]{2}{*}{$P$ value } & \multirow[t]{2}{*}{ OR $(95 \% \mathrm{CI})$} \\
\hline & $\mathrm{N}=327$ & $\%$ & $\mathrm{~N}=327$ & $\%$ & & & \\
\hline Age (years, mean \pm SD) & \multicolumn{2}{|c|}{$56.2 \pm 11.3$} & \multicolumn{2}{|c|}{$55.8 \pm 10.7$} & & 0.14 & \\
\hline \multicolumn{8}{|l|}{ Gender } \\
\hline Female & 103 & 31.50 & 103 & 31.50 & & & \\
\hline Male & 224 & 68.50 & 224 & 68.50 & 0 & 1 & $1.00(0.71-1.41)$ \\
\hline \multicolumn{8}{|l|}{ Tobacco smoking } \\
\hline No & 201 & 61.47 & 220 & 67.28 & & & 1.00 (Ref.) \\
\hline Yes & 126 & 38.53 & 107 & 32.72 & 2.41 & 0.12 & $1.29(0.92-1.80)$ \\
\hline \multicolumn{8}{|l|}{ Alcohol consumption } \\
\hline No & 211 & 64.53 & 239 & 73.09 & & & 1.00 (Ref.) \\
\hline Yes & 116 & 35.47 & 88 & 26.91 & 5.59 & 0.02 & $1.49(1.06-2.11)$ \\
\hline \multicolumn{8}{|l|}{ Viral infection } \\
\hline Both negative & 160 & 48.93 & 283 & 86.54 & & & 1.00 (Ref.) \\
\hline HBV infection & 132 & 40.37 & 38 & 11.62 & & $<0.001$ & $6.14(4.01-9.50)$ \\
\hline $\mathrm{HCV}$ infection & 32 & 9.79 & 6 & 1.83 & & $<0.001$ & $9.43(3.77-28.07)$ \\
\hline Both positive & 3 & 0.92 & 0 & 0.00 & 154.46 & - & - \\
\hline \multicolumn{8}{|l|}{ Tumor size } \\
\hline$<5 \mathrm{~cm}$ & 200 & 61.16 & & & & & \\
\hline$\geq 5 \mathrm{~cm}$ & 127 & 38.84 & & & & & \\
\hline \multicolumn{8}{|l|}{ TNM stage } \\
\hline I-II & 195 & 59.63 & & & & & \\
\hline III-IV & 132 & 40.37 & & & & & \\
\hline
\end{tabular}


The genotype frequencies of miR-149C $>\mathrm{T}$ in $\mathrm{HCC}$ patients and control subjects are shown in Table 2. The miR-149C $>\mathrm{T}$ genetic distributions in controls were in accordance with Hardy-Weinberg equilibrium (HWE) expectations, which showed that no selection bias existed ( $\mathrm{P}$ for HWE was 0.06). There was significant difference in the genotype frequencies of miR-149C $>\mathrm{T}$ between cases and controls $\left(\chi^{2}=10.36, \mathrm{P}=0.006\right)$. Logistical regression analysis showed that the miR-149 CC genotype and C allele were associated with risk of HCC, with adjusted ORs $(95 \% \mathrm{CI})$ of 2.07 (1.32-3.26) and 1.42 (1.06-2.12), respectively. Using the $\mathrm{TT}+\mathrm{TC}$ genotype as a reference, individuals carrying the $\mathrm{CC}$ genotypes were associated with non-significant increased risk of HCC, adjusted OR (95\%CI) of 1.37 (0.91-2.07).

\begin{tabular}{|c|c|c|c|c|c|c|c|c|c|}
\hline $\mathrm{miR}-149 \mathrm{C}>\mathrm{T}$ & Cases & $\%$ & Controls & $\%$ & P for HWE & $\chi^{2}$ & $P$ value & Adjusted OR $(95 \% \mathrm{CI})^{\mathrm{a}}$ & $P$ value \\
\hline \multicolumn{10}{|l|}{ Genotype } \\
\hline TT & 100 & 30.58 & 133 & 40.67 & & & & 1.0 (Ref.) & \\
\hline $\mathrm{TC}$ & 143 & 43.73 & 138 & 42.20 & & & & $1.41(0.98-2.13)$ & 0.07 \\
\hline $\mathrm{CC}$ & 84 & 25.69 & 56 & 17.13 & 0.06 & 10.36 & 0.006 & $2.07(1.32-3.26)$ & 0.002 \\
\hline \multicolumn{10}{|c|}{ Dominant model } \\
\hline TT & 106 & 32.42 & 125 & 38.23 & & & & 1.0 (Ref.) & \\
\hline $\mathrm{TC}+\mathrm{CC}$ & 227 & 69.42 & 202 & 61.77 & & 2.97 & 0.085 & $1.42(1.06-2.12)$ & 0.04 \\
\hline \multicolumn{10}{|c|}{ Recessive model } \\
\hline $\mathrm{TT}+\mathrm{TC}$ & 243 & 74.31 & 263 & 80.43 & & & & 1.0 (Ref.) & \\
\hline $\mathrm{CC}$ & 78 & 23.85 & 64 & 19.57 & & 2.12 & 0.15 & $1.37(0.91-2.07)$ & 0.11 \\
\hline
\end{tabular}

Stratified analysis was conducted to assess whether the effect of miR-149C $>$ T polymorphism was influenced by viral infection and alcohol consumption (Table 3). Subgroup analysis showed that the effect of miR-149C $>\mathrm{T}$ polymorphism was modified by viral infection. HBV-infected subjects carrying the miR-149 $\mathrm{TC}+\mathrm{CC}$ genotype $(\mathrm{OR}=5.85,95 \% \mathrm{CI}=$ 2.49-13.77) had an increased risk of HCC. However, the miR-149C $>$ T polymorphism was not associated with a significantly enhanced risk of HCC in both HBV and HCV-negative and $\mathrm{HCV}$-infected subjects. In addition, we did not observe effect of alcohol drinking on the association between miR-149C $>$ T polymorphisms and HCC risk.

\begin{tabular}{|c|c|c|c|c|c|c|}
\hline \multirow[t]{3}{*}{$\mathrm{miR}-149 \mathrm{C}>\mathrm{T}$} & \multicolumn{4}{|c|}{ Genotype } & \multirow[t]{3}{*}{ Adjusted OR $(95 \% \mathrm{CI})$} & \multirow[t]{3}{*}{ P value } \\
\hline & \multicolumn{2}{|c|}{ TT } & \multicolumn{2}{|c|}{$\mathrm{TC}+\mathrm{CC}$} & & \\
\hline & Case & Control & Case & Control & & \\
\hline \multicolumn{7}{|l|}{ Viral infection ${ }^{\mathrm{a}}$} \\
\hline Both negative & 62 & 99 & 98 & 184 & $0.85(0.56-1.30)$ & 0.45 \\
\hline HBV & 23 & 21 & 109 & 17 & $5.85(2.49-13.77)$ & $<0.001$ \\
\hline $\mathrm{HCV}$ & 18 & 5 & 14 & 1 & $3.11(0.26-163.9)$ & 0.31 \\
\hline \multicolumn{7}{|c|}{ Alcohol consumption ${ }^{\mathrm{b}}$} \\
\hline No & 61 & 83 & 150 & 156 & $1.31(0.86-1.99)$ & 0.19 \\
\hline Yes & 45 & 42 & 71 & 46 & $1.44(0.79-2.62)$ & 0.2 \\
\hline
\end{tabular}

\section{DISCUSSION}

Our study showed the allele frequencies were similar to frequencies given for Chinese 
populations in the NCBI databases, which showed the control group has a better representation for the general population in China. Moreover, we found that miR-149 CC genotype and $\mathrm{C}$ allele increase the risk of $\mathrm{HCC}$, especially in $\mathrm{HBV}$ infection patients. Our study suggested that miR-149C $>\mathrm{T}$ polymorphisms can be used as a diagnostic marker for $\mathrm{HCC}$, and help in reducing HCC mortality through early screening and diagnosis.

Previous studies have reported that aberrant regulation of specific miRNAs and their targets in various kinds of cancer is associated with cancer growth angiogenesis and metastasis (Esquela-Kerscher and Slack, 2006; Croce, 2009). Regarding miR-149C $>$ T, it is a proapoptotic miRNA to repress the expression of Akt1 and E2F1. Silencing of Akt1 and E2F1 can induce apoptosis in human tumor cell lines (Lin et al., 2010, 2011). Previous studies showed that polymorphism in miR-149C $>$ T can change the expression of mature miRNAs or the binding activities to target mRNA, and thus influence cancer risk through various mechanisms (Lin et al., 2010, 2011). Previous studies reported that the association between polymorphism in miR-149C $>\mathrm{T}$ and risk of various cancers, such as breast cancer, lung cancer, head and neck cancer, colorectal cancer and HCC, but the results are inconsistent (Hu et al., 2009; Liu et al., 2010; Vinci et al., 2011; Kim et al., 2012; Du et al., 2014). Hu et al. (2009) reported a study on the association between miR-149C $>\mathrm{T}$ polymorphism and risk of breast cancer, and showed that miR-149C $>\mathrm{T}$ polymorphism is not associated with risk of this cancer. Vinci et al. (2011) conducted a study in Italy and reported that no association was found between miR$149 \mathrm{C}>\mathrm{T}$ polymorphism and risk of breast cancer. Liu et al. (2010) reported that miR-149C $>\mathrm{T}$ polymorphism is associated with risk of head and neck cancer. Zhang et al. (2012) conducted a meta-analysis with eight studies including 4677 cases and 4830 controls, and showed that miR-149C $>$ T polymorphism may not contribute to cancer susceptibility. The discrepancy of the results may be explained by the differences in cancer types, ethnicities, source of cases, sample size, and also by chance.

For HCC, only one study reported the association between miR-149C $>\mathrm{T}$ polymorphism and risk of HCC (Kim et al., 2012). Kim et al. (2012) conducted a study in South Korea with $159 \mathrm{HCC}$ patients and 201 controls, and reported that the risk of HCC was significantly lower for the miR-149C $>$ T, especially in HBV-related HCC patients. Our study found that miR-149C $>\mathrm{T}$ CC genotype was associated with an increased risk of HCC, which is inconsistent with the previous one. Therefore, further large sample studies with different ethnic backgrounds were greatly needed to confirm their association.

Stratified analysis showed that the association between miR-149C $>\mathrm{T}$ polymorphisms and $\mathrm{HCC}$ risk were modified by $\mathrm{HBV}$ infection, suggesting that variation of miR-149C $>\mathrm{T}$ may be involved in immune regulation during HBV infection. Previous experimental study showed that HBV replication modifies the expression of host cellular miRNAs, and thus influence the carcinogenesis of liver by HBV (Kim et al., 2012). Kim et al. (2012) reported that miR-149C $>$ T polymorphism is associated with HBV-related HCC patients. Several limitations should be considered in our study. First, cases were selected from one hospital, which may not be representative of the general population. However, all control subjects in our study were in line with HWE, which could better represent the general population. Second, the sample size of our study is relatively small, which may reduce the statistical power to find the difference between groups. Therefore, further large sample, multicenter studies including different ethnicities are warranted to investigate the association between miR-149C $>\mathrm{T}$ and the risk of HCC. 
In summary, our study found that miRNA-149C $>$ T polymorphism is associated with risk of HCC, especially in HBV-infected patients. Our study suggests that miRNA-149C $>$ T polymorphisms may be useful as predictive markers for detecting of high-risk individuals such as HBV-infected subjects who are at an even greater risk for HCC.

\section{REFERENCES}

Calin GA and Croce CM (2006). MicroRNA signatures in human cancers. Nat. Rev. Cancer 6: 857-866.

$\mathrm{Chu}$ YH, Hsieh MJ, Chiou HL, Liou YS, et al. (2014). MicroRNA gene polymorphisms and environmental factors increase patient susceptibility to hepatocellular carcinoma. PLoS One 9: e89930.

Croce CM (2009). Causes and consequences of microRNA dysregulation in cancer. Nat. Rev. Genet. 10: 704-714.

Du W, Ma XL, Zhao C, Liu T, et al. (2014). Associations of single nucleotide polymorphisms in miR-146a, miR-196a, miR-149 and miR-499 with colorectal cancer susceptibility. Asian Pac. J. Cancer Prev. 15:1047-1055.

Esquela-Kerscher A and Slack FJ (2006). Oncomirs - microRNAs with a role in cancer. Nat. Rev. Cancer 6: 259-269.

Hatfield SD, Shcherbata HR, Fischer KA, Nakahara K, et al. (2005). Stem cell division is regulated by the microRNA pathway. Nature 435: 974-978.

He B, Pan Y, Cho WC, Xu Y, et al. (2012). The association between four genetic variants in microRNAs (rs11614913, rs2910164, rs3746444, rs2292832) and cancer risk: evidence from published studies. PLoS One 7: e49032.

Hu Z, Liang J, Wang Z, Tian T, et al. (2009). Common genetic variants in pre-microRNAs were associated with increased risk of breast cancer in Chinese women. Hum. Mutat. 30:79-84.

IARC (International Agency for Research on Cancer) (2008). Globocan 2008 in China. Available at [http://globocan.iarc. fr/factsheet.asp]. Accessed October 1, 2013.

Jang MJ, Kim JW, Min KT, Jeon YJ, et al. (2011). Prognostic significance of microRNA gene polymorphisms in patients with surgically resected colorectal cancer. Exp. Ther. Med. 2: 1127-1132.

Kao JH and Chen DS (2002). Global control of hepatitis B virus infection. Lancet Infect. Dis. 2: 395-403.

Kim WH, Min KT, Jeon YJ, Kwon CI, et al. (2012). Association study of microRNA polymorphisms with hepatocellular carcinoma in Korean population. Gene 504: 92-97.

Lin RJ, Lin YC and Yu AL (2010). miR-149* induces apoptosis by inhibiting Akt1 and E2F1 in human cancer cells. Mol. Carcinog. 49: 719-727.

Lin T, Ding Z, Li N, Xu J, et al. (2011). 2-Tellurium-bridged $\beta$-cyclodextrin, a thioredoxin reductase inhibitor, sensitizes human breast cancer cells to TRAIL-induced apoptosis through DR5 induction and NF-kB suppression. Carcinogenesis 32: 154-167.

Liu Z, Li G, Wei S, Niu J, et al. (2010). Genetic variants in selected pre-microRNA genes and the risk of squamous cell carcinoma of the head and neck. Cancer 116: 4753-4760.

Mishra PJ and Bertino JR (2009). MicroRNA polymorphisms: the future of pharmacogenomics, molecular epidemiology and individualized medicine. Pharmacogenomics 10: 399-416.

Vinci S, Gelmini S, Pratesi N, Conti S, et al. (2011). Genetic variants in miR-146a, miR-149, miR-196a2, miR-499 and their influence on relative expression in lung cancers. Clin. Chem. Lab. Med. 49: 2073-2080.

Zhang J, Liu YF and Gan Y (2012). Lack of association between miR-149 C > T polymorphism and cancer susceptibility: a meta-analysis based on 4,677 cases and 4,830 controls. Mol. Biol. Rep. 39: 8749-8753. 